\title{
Synthesis of Carbazoles by a Diverted Bischler-Napieralski Cascade Reaction
}

\author{
Matteo Faltracco, Said Ortega-Rosales, Elwin Janssen, Răzvan C. Cioc, Christophe M. L. Vande Velde, \\ and Eelco Ruijter*
}

Cite This: Org. Lett. 2021, 23, 3100-3104

Read Online

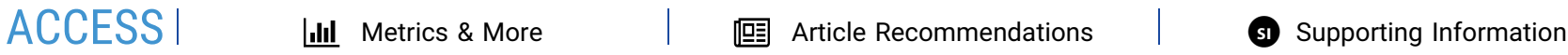

ABSTRACT: An unforeseen twist in a seemingly trivial BischlerNapieralski reaction led to the selective formation of an unexpected carbazole product. The reaction proved to be general, providing access to a range of diversely substituted carbazoles from readily available substrates. Judicious variation of substituents revealed a complex cascade mechanism comprising no less than 10 elementary steps, that could be diverted in multiple ways toward various other carbazole derivatives.

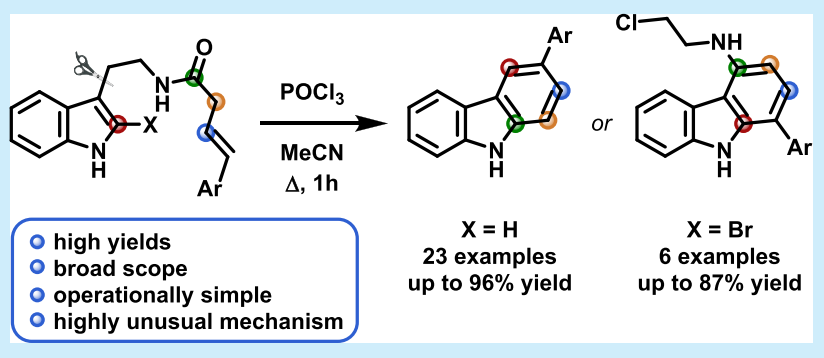

ince its first report in 1893, the Bischler-Napieralski $\checkmark$ reaction has been widely employed for the synthesis of dihydro- $\beta$-carbolines and -isoquinolines owing to its robustness and broad functional group tolerance. ${ }^{1}$ Even currently, the Bischler-Napieralski reaction and its contemporary variations are still the object of intensive study in many areas, including natural product synthesis. ${ }^{2}$ In light of our interest in bioactive indole alkaloids and related compounds, ${ }^{3}$ we employed the Bischler-Napieralski reaction to access a series of dihydro- $\beta$ carbolines. However, when we subjected styrylacetamide $\mathbf{1 a}$ to typical Bischler-Napieralski conditions $\left(\mathrm{POCl}_{3}, \mathrm{MeCN}\right.$, reflux, $1 \mathrm{~h}$ ) we serendipitously found near-quantitative formation of 3phenylcarbazole (3a) instead of the expected dihydro- $\beta$ carboline 2a (Scheme 1A). The structure of $\mathbf{3 a}$ was confirmed by ${ }^{1} \mathrm{H}$ and ${ }^{13} \mathrm{C}$ NMR, HRMS, and X-ray crystallography.

Although carbazoles are less common than the related indoles among natural products and medicinal compounds, various carbazoles displaying interesting properties have been reported (Scheme 1B). ${ }^{4}$ Notable examples include the anticancer natural products staurosporine ${ }^{5}$ (and its clinically used semisynthetic derivative, midostaurin ${ }^{6}$ ) and ellipticine. ${ }^{7}$

Recently, carbazole derivative 4 was identified as a lead for new antitrypanosomiasis drugs, ${ }^{8}$ while glycozoline is known for its antibacterial, antifungal, antifeedant, and anti-inflammatory properties. ${ }^{9}$ Typical methods for the synthesis of carbazoles involve high temperature, long reaction times, and often metal catalysis (sometimes replaced by iodine or Lewis acids). ${ }^{10,11}$ Intrigued by our preliminary result, we decided to further explore the synthetic potential of this novel, mild, and metalfree route to carbazoles in more detail.

Puzzled by the surprising, but highly efficient formation of 3a, we set out to investigate the generality of the process. A series of diversely substituted tryptamides $\mathbf{1 a}-\mathbf{t}$ was subjected to the reaction conditions $\left(\mathrm{POCl}_{3}, \mathrm{MeCN}\right.$, reflux, $\left.1 \mathrm{~h}\right)$.
Scheme 1. (A) Unexpected Carbazole Formation; (B) Bioactive Carbazoles
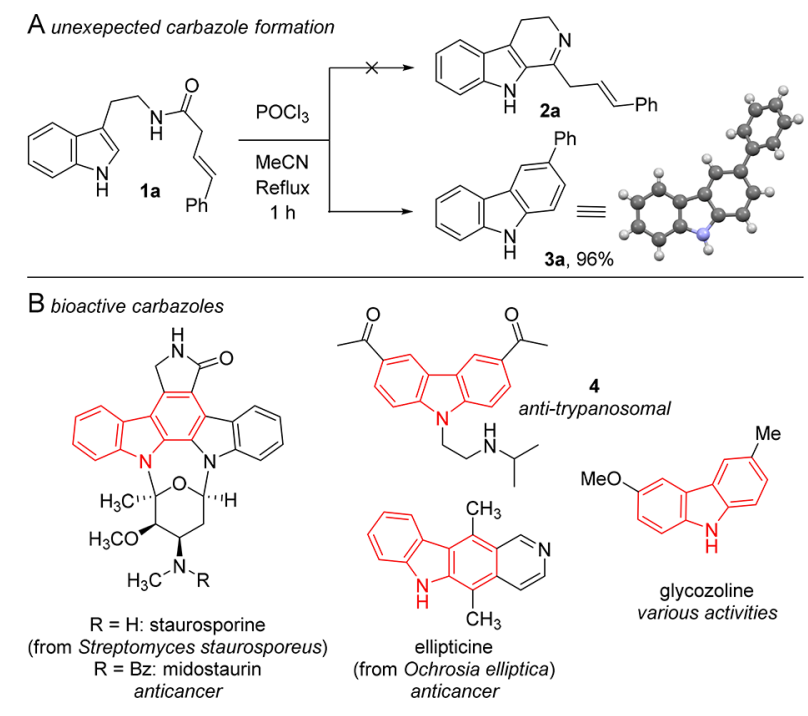

Pleasingly, we observed that all substrates underwent full conversion within $1 \mathrm{~h}$ (Scheme 2). Both electron-withdrawing and electron-donating substituents on the indole $\left(\mathrm{R}^{2}\right)$ are tolerated without significant influence on the yield, affording the corresponding products $\mathbf{3 b}-\mathbf{k}$ in mostly good yield, with 5-

Received: March 6, 2021

Published: March 31, 2021 
Scheme 2. Scope of the Carbazole Formation ${ }^{a}$

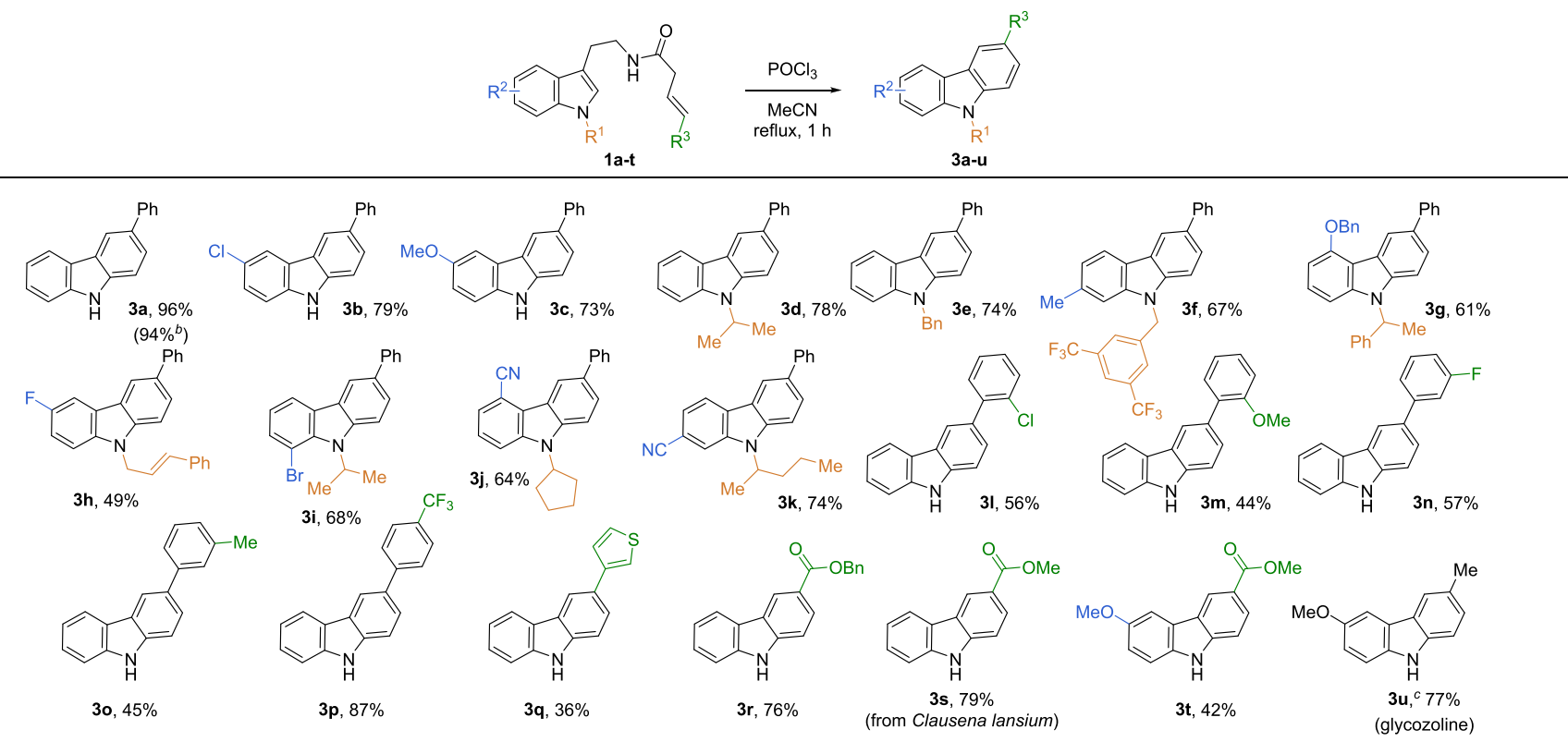

${ }^{a}$ All reactions were performed with $0.2 \mathrm{mmol}$ of $\mathbf{1 a}-\mathbf{t}, 0.3 \mathrm{mmol}$ of $\mathrm{POCl}_{3}$, refluxing in $\mathrm{MeCN}$ for $1 \mathrm{~h} .{ }^{b}$ Performed on a $2 \mathrm{mmol}$ scale. ${ }^{c} \mathrm{Obtained}$ by treatment of $2 \mathrm{t}$ with $\mathrm{LiAlH}_{4}$.

fluoro substitution giving the lowest yield (3h, 49\%). Similarly, $N$-alkyl substituents had very little effect on the reaction outcome $(3 \mathbf{d}-\mathbf{k})$. The effect of varying $\mathrm{R}^{3}$ substitution is more significant. Electron-deficient arenes as $\mathrm{R}^{3}$ substituents perform best (31, $3 \mathbf{n}$, and especially $3 \mathbf{p}$ ). In contrast, products bearing an electron-rich aryl $(3 \mathrm{~m}, 3 \mathbf{3 o})$ or 3 -thienyl $\mathrm{R}^{3}$ substituent (3q) were obtained in lower yields. Interestingly, esters as the $\mathrm{R}^{3}$ substituent were also able to promote the transformation, affording the corresponding carbazoles in high yield when the indole core is unsubstituted $\left(3 \mathbf{r}, \mathbf{s}, \mathrm{R}^{1}=\mathrm{R}^{2}=\mathrm{H}\right)$ and in moderate yield when a 5-methoxy group is present (3t). Treatment of 3t with $\mathrm{LiAlH}_{4}$ afforded the natural product glycozoline $(3 \mathbf{u})$ which, together with $3 \mathbf{s}$, has been isolated from Clausena lansium. ${ }^{12}$

Once we established the generality of the reaction, we began our mechanistic investigation by the systematic variation of the substitution of the styrylacetic acid moiety in 1a (Scheme 3). Reaction of the $\gamma$-methyl-substituted styrylacetamide $\mathbf{1} \mathbf{u}$ led to a complex reaction mixture containing traces of the corresponding regular Bischler-Napieralski product, but no carbazole derivatives. Reaction of the $\beta$-methyl-substituted substrate $1 \mathbf{v}$ gave 2 -methylcarbazole $3 \mathbf{v}$, while $\alpha$-methylsubstituted styrylacetamide $\mathbf{1 w}$ afforded 1-methylcarbazole $3 \mathbf{w}$.

These results may be rationalized by either transfer of the cinnamyl moiety to the indole $\mathrm{C} 2$ position or a complete rearrangement of the starting material involving ring opening of the indole moiety. The reaction of $1 x$, bearing a methyl substituent at the indole $\mathrm{C} 2$ position, surprisingly afforded 4methyl-3-phenylcarbazole ( $3 \mathbf{x})$. The formation of $3 \mathbf{x}$ can only be rationalized by a methyl migration or ring opening of the indole. Finally, we employed ${ }^{13} \mathrm{C}$-labeled substrate $1 \mathrm{a}^{* 13}$ and observed the incorporation of the ${ }^{13} \mathrm{C}$ label at the $9 a$ position of carbazole $3 \mathrm{a}^{*}$.

Based on the results summarized in Scheme 3 and relevant prior literature, ${ }^{14}$ we could postulate a mechanism to rationalize the formation of $\mathbf{3 a}$ from $\mathbf{1 a}$ (Scheme 4). Plausibly, the reaction is initiated by the formation of nitrilium ion $\mathbf{5}$,
Scheme 3. Systematic Methyl Substitution

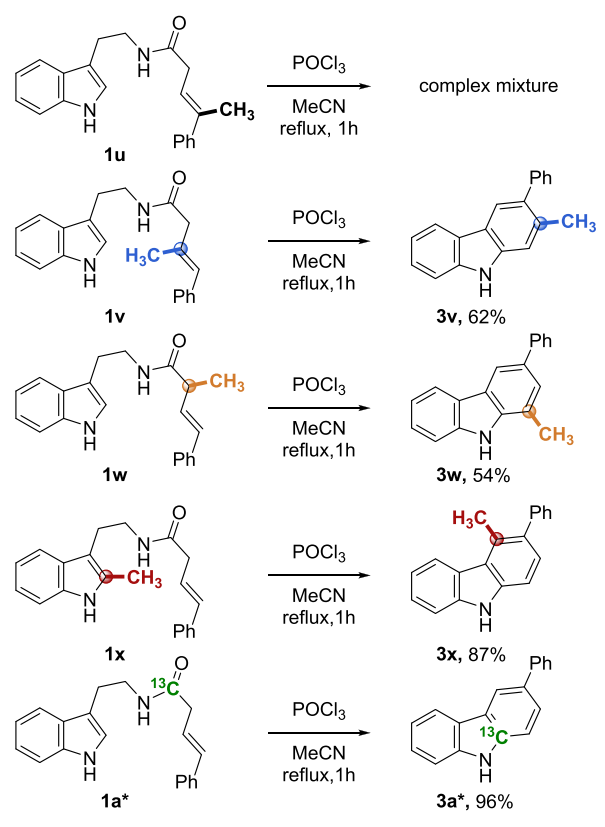

which undergoes attack by the indole $\mathrm{C} 3$ position to give spiroindolenine derivative $\mathbf{6}$. In the Bischler-Napieralski reaction, $\mathbf{6}$ undergoes a rapid Plancher rearrangement, leading to dihydro- $\beta$-carboline $2 \mathrm{a}$ after deprotonation of 7 . In this case, however, the presence of the styryl moiety makes tautomerization to 8 more favorable. The resulting vinylogous enamine attacks the protonated indolenine, leading to formation of the tetracyclic scaffold 9. Then, $\beta$-elimination of the (protonated) aromatic amine takes place, opening up the indoline ring in $\mathbf{1 0 .}$ The resulting aniline $\mathbf{1} 1$ subsequently undergoes imine transfer (via the bridged aminal 12) to form the carbazole framework. The resulting dihydrocarbazole 13 finally undergoes attack by 


\section{Scheme 4. Postulated Mechanism}

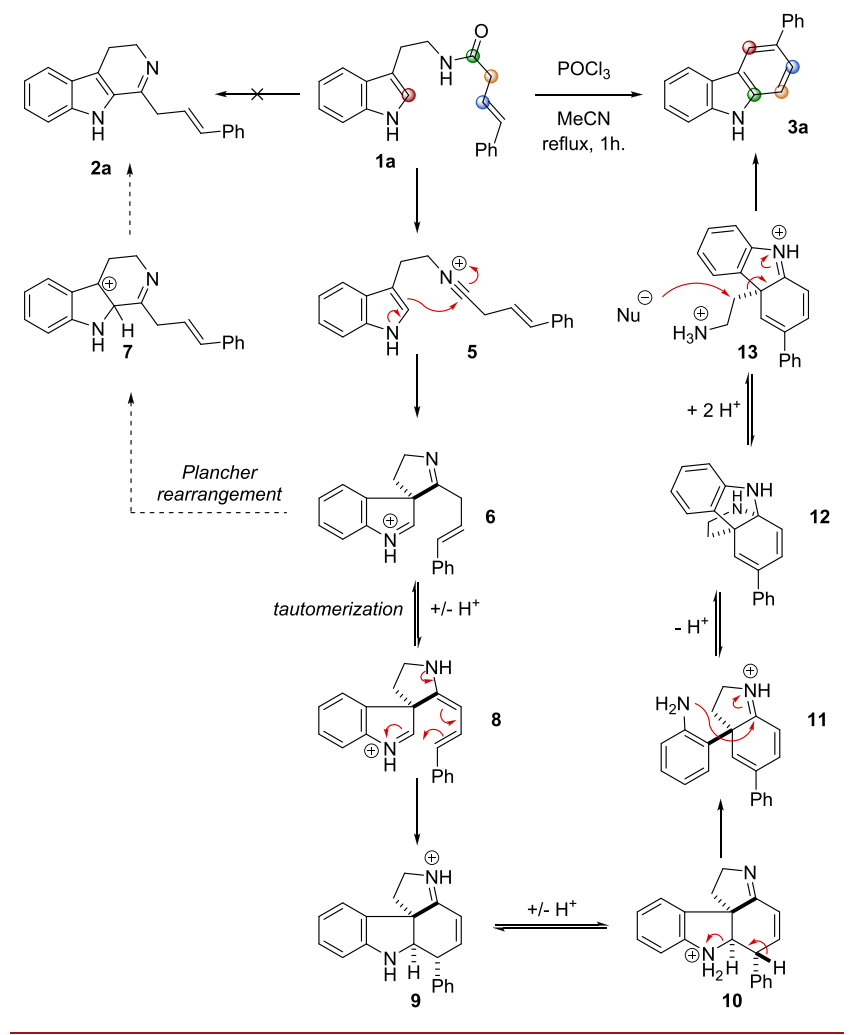

an unidentified nucleophile (most likely chloride) to give 3a with aromatization as a strong thermodynamic driving force.

Once we established a plausible mechanism, we realized that this complex, multistep transformation offers numerous opportunities for interruption or diversion of the reaction by judicious selection of substituents. First, we explored the possibility of diverting the cascade process by considering the equilibrium between 11,12 , and 13 that ultimately leads to the formation of 3a. We reasoned that the nucleophilic attack that takes place on the $\mathrm{sp}^{3}$ carbon of $\mathbf{1 3}$ could be avoided if the aliphatic linker is replaced by an aromatic one. Indeed, subjecting the phenylene-linked amide $1 \mathbf{y}$ to the cyclization conditions afforded carbazole $\mathbf{1 4}$ in $\mathbf{7 5 \%}$ yield (Scheme 5). Based on the above-mentioned considerations, we expected that the cascade would proceed analogously to the formation of 3a until intermediate $\mathbf{1 7}$ and be interrupted at that stage. However, aromatization proved too great a driving force also in this case. As $\mathrm{S}_{\mathrm{N}} 2$ substitution is not possible in this case (cf. 13

Scheme 5. Aromatic Linker Diversion
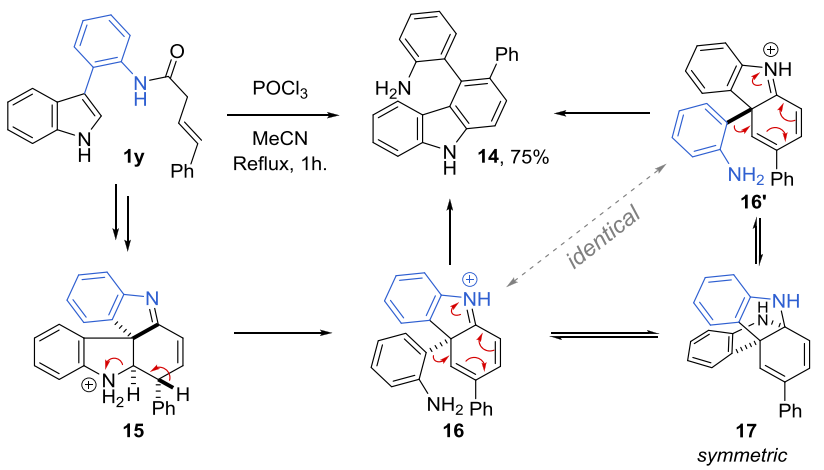

to 3a, Scheme 4), the 1,2-aryl migration of the aniline fragment in $\mathbf{1 6}$ would re-establish the aromaticity of the system in the final stage. It is interesting to note that aminal intermediate $\mathbf{1 7}$ has an internal mirror plane and the two iminium species 16 and $16^{\prime}$ are identical, thus leading to the formation of a single carbazole product (14).

Next, we focused our attention on intermediate 10 (Scheme 4), the tetracyclic core of which is present in a variety of natural products. ${ }^{15}$ To target this scaffold, ring opening of the indole (leading to $\mathbf{1 1}$, Scheme 4) needs to be prevented. Thus, we synthesized C2 Br-substituted styrylacetamide 18a to offer an alternative elimination pathway, interrupting the cascade at this stage. Indeed, the reaction of 18a does undergo a diverted pathway; however, the product was again a carbazole (19a, Scheme 6), albeit with yet another surprising substitution

Scheme 6. C2 Bromide Diversion

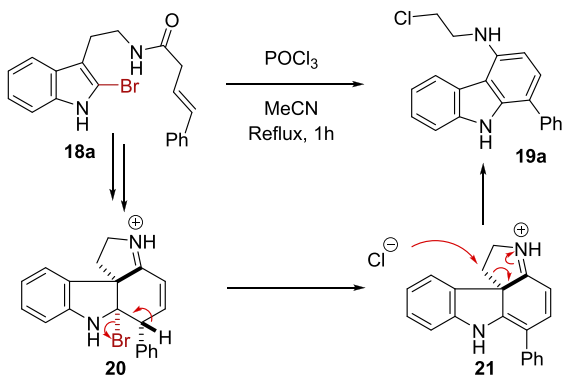

pattern. The formation of 19a could be rationalized by an alternative evolution of intermediate 20. At this point, elimination of $\mathrm{HBr}$ is favored over indoline ring opening, leading to 21. Similarly to the conversion of 13 to 3a (Scheme 4), attack of a chloride anion would terminate the cascade to give carbazole 19a.

We then proceeded to demonstrate the generality of this alternative transformation (Scheme 7). All desired products $19 a-f$ were obtained in moderate to very good yield, although we observed higher yields for products bearing electronwithdrawing substituents such as halogens and $\mathrm{CF}_{3}(19 \mathrm{~b}, 19 \mathrm{~d}$, $19 e)$, yet the highest yield was observed for the unsubstituted

Scheme 7. Scope of C2 Bromide Diversion ${ }^{a}$
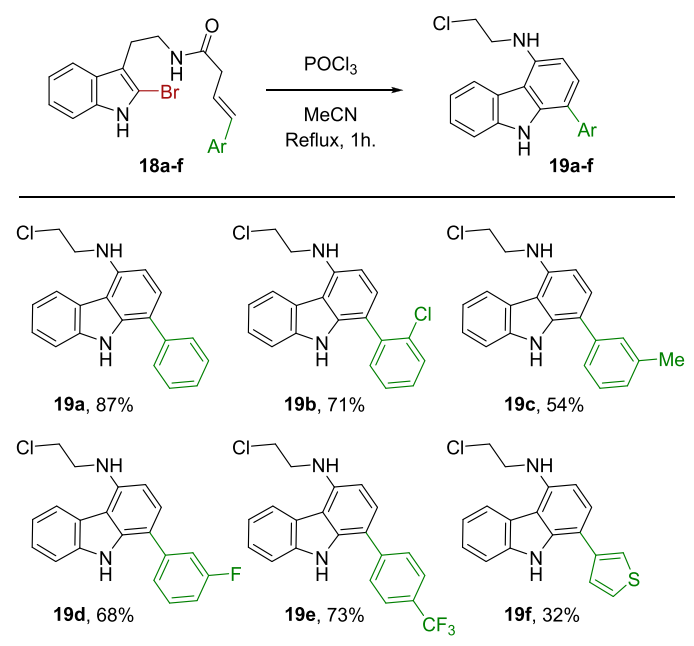

${ }^{a}$ All reactions were performed with $0.2 \mathrm{mmol}$ of $\mathbf{1 8 a}-\mathbf{f}, 0.3 \mathrm{mmol}$ of $\mathrm{POCl}_{3}$, refluxing in $\mathrm{MeCN}$ for $1 \mathrm{~h}$. 
product 19a. In contrast, the presence of a methyl substituent led to a lower yield (19c), whereas replacing the phenyl ring with a thienyl moiety reduced the yield significantly (19f).

In conclusion, we report the serendipitous discovery of a diverted Bischler-Napieralski cascade reaction yielding carbazoles. The method features metal-free conditions, good yields, and high functional group tolerance. Systematic experimentation allowed us to confidently establish a complex multistep reaction mechanism, which allowed for straightforward further diversion or interruption of the reaction pathway to give different carbazole regioisomers. Efforts to further exploit the tetracyclic intermediates in the reaction in the total synthesis of indole alkaloids are currently ongoing in our laboratory.

\section{ASSOCIATED CONTENT}

\section{SI Supporting Information}

The Supporting Information is available free of charge at https://pubs.acs.org/doi/10.1021/acs.orglett.1c00785.

Experimental details and characterization data, ${ }^{1} \mathrm{H}$ and ${ }^{13} \mathrm{C}$ NMR spectra, 2D NMR spectra (PDF)

FAIR data, including the primary NMR FID files, for compounds $1 \mathrm{a}-\mathrm{y}, 3 \mathrm{a}-\mathrm{x}, 14,18 \mathrm{a}-\mathrm{f}$ and 19a-f (ZIP)

\section{Accession Codes}

CCDC 2062984 contains the supplementary crystallographic data for this paper. These data can be obtained free of charge via www.ccdc.cam.ac.uk/data_request/cif, or by emailing data_request@ccdc.cam.ac.uk, or by contacting The Cambridge Crystallographic Data Centre, 12 Union Road, Cambridge CB2 1EZ, UK; fax: +44 1223336033.

\section{AUTHOR INFORMATION}

\section{Corresponding Author}

Eelco Ruijter - Department of Chemistry \& Pharmaceutical Sciences, Amsterdam Institute of Molecular \& Life Sciences (AIMMS), Vrije Universiteit Amsterdam, 1081, HZ, Amsterdam, The Netherlands; 이이이.org/0000-00021105-3947; Email: e.ruijter@vu.nl

\section{Authors}

Matteo Faltracco - Department of Chemistry \& Pharmaceutical Sciences, Amsterdam Institute of Molecular \& Life Sciences (AIMMS), Vrije Universiteit Amsterdam, 1081, HZ, Amsterdam, The Netherlands

Said Ortega-Rosales - Department of Chemistry \& Pharmaceutical Sciences, Amsterdam Institute of Molecular \& Life Sciences (AIMMS), Vrije Universiteit Amsterdam, 1081, HZ, Amsterdam, The Netherlands

Elwin Janssen - Department of Chemistry \& Pharmaceutical Sciences, Amsterdam Institute of Molecular \& Life Sciences (AIMMS), Vrije Universiteit Amsterdam, 1081, HZ, Amsterdam, The Netherlands

Răzvan C. Cioc - Organic Chemistry and Catalysis, Debye Institute for Nanomaterials Science, Utrecht University, 3584, CG, Utrecht, The Netherlands

Christophe M. L. Vande Velde - Faculty of Applied Engineering, iPRACS, University of Antwerp, 2020 Antwerpen, Belgium

Complete contact information is available at: https://pubs.acs.org/10.1021/acs.orglett.1c00785

\section{Notes}

The authors declare no competing financial interest.

\section{ACKNOWLEDGMENTS}

This work was financially supported by The Netherlands Organisation for Scientific Research (NWO).We thank Xander Schaapkens and Ad Ruigrok van de Werve for preliminary experiments and Daniël Preschel for HRMS measurements (all VUA). We thank the Hercules Foundation (Project AUGE/ 11/029 "3D-SPACE: 3D Structural Platform Aiming for Chemical Excellence") for funding the diffractometer, and Prof. Kristof Van Hecke (University of Ghent) for making available diffractometer time.

\section{REFERENCES}

(1) Bischler, A.; Napieralski, B. Zur Kenntniss einer neuen Isochinolinsynthese. Ber. Dtsch. Chem. Ges. 1893, 26, 1903-1908.

(2) (a) Wang, S.; Si, R.; Zhuang, Q.; Guo, X.; Ke, T.; Zhang, X.; Zhang, F.; Tu, Y. Collective Total Synthesis of Aspidofractinine Alkaloids through the Development of a Bischler-Napieralski/ Semipinacol Rearrangement Reaction. Angew. Chem., Int. Ed. 2020, 59, 21954-21958. (b) Magnus, P.; Payne, A. H.; Hobson, L. Synthesis of the Kopsia alkaloids $( \pm)$-11,12-demethoxylahadinine B, $( \pm)$-kopsidasine and ( \pm )-kopsidasine- $N$-oxide. Tetrahedron Lett. 2000, 41, 2077-2081. (c) Mewald, M.; Medley, J. W.; Movassaghi, M. Concise and Enantioselective Total Synthesis of (-)-Mehranine, (-)-Methylenebismehranine, and Related Aspidosperma Alkaloids. Angew. Chem., Int. Ed. 2014, 53, 11634-11639. (d) White, K. L.; Movassaghi, M. Concise Total Syntheses of (+)-Haplocidine and (+)-Haplocine via Late-Stage Oxidation of (+)-Fendleridine Derivatives. J. Am. Chem. Soc. 2016, 138, 11383-11389. (e) Kang, T.; White, K. L.; Mann, T. J.; Hoveyda, A. H.; Movassaghi, M. Enantioselective Total Synthesis of (-)-Deoxoapodine. Angew. Chem., Int. Ed. 2017, 56, 13857-13860. (f) Magnus, P.; Gazzard, L.; Hobson, L.; Payne, A. H.; Lynch, V. Studies on the synthesis of the indole alkaloids pauciflorine A and B. Tetrahedron Lett. 1999, 40, 5135-5138.

(3) (a) de Graaff, C.; Bensch, L.; Boersma, S. J.; Cioc, R. C.; van Lint, M. J.; Janssen, E.; Turner, N. J.; Orru, R. V. A.; Ruijter, E. Asymmetric Synthesis of Tetracyclic Pyrroloindolines and Constrained Tryptamines by a Switchable Cascade Reaction. Angew. Chem., Int. Ed. 2015, 54, 14133-14136. (b) Saya, J. M.; van Wordragen, E. D. H.; Orru, R. V. A.; Ruijter, E. Mild and Practical Indole C2 Allylation by Allylboration of in situ Generated 3Chloroindolenines. Eur. J. Org. Chem. 2019, 2019, 5156-5160. (c) Saya, J. M.; Roose, T. R.; Peek, J. J.; Weijers, B.; de Waal, T. J. S.; Vande Velde, C. M. L.; Orru, R. V. A.; Ruijter, E. Iodospirocyclization of Tryptamine-Derived Isocyanides: Formal Total Synthesis of Aspidofractinine. Angew. Chem., Int. Ed. 2018, 57, 15232-15236.

(4) For reviews, see: (a) Schmidt, A. W.; Reddy, K. R.; Knölker, H.J. Occurrence, Biogenesis, and Synthesis of Biologically Active Carbazole Alkaloids. Chem. Rev. 2012, 112, 3193-3328. (b) Bauer, I.; Knölker, H.-J. Synthesis of pyrrole and carbazole alkaloids. Top. Curr. Chem. 2011, 309, 203-253.

(5) Stepczynska, A.; Lauber, K.; Engels, I. H.; Janssen, O.; Kabelitz, D.; Wesselborg, S.; Schulze-Osthoff, K. Staurosporine and conventional anticancer drugs induce overlapping, yet distinct pathways of apoptosis and caspase activation. Oncogene 2001, 20, 1193-1202.

(6) Hsiao, S.-H.; Lusvarghi, S.; Huang, Y.-H.; Ambudkar, S. V.; Hsu, S.-C.; Wu, C.-P. The FLT3 inhibitor midostaurin selectively resensitizes $\mathrm{ABCB} 1$-overexpressing multidrug-resistant cancer cells to conventional chemotherapeutic agents. Cancer Lett. 2019, 445, 3444.

(7) Auclair, C. Multimodal action of antitumor agents on DNA: The ellipticine series Arch. Arch. Biochem. Biophys. 1987, 259, 1-14. 
(8) Thomas, S. M.; Purmal, A.; Pollastri, M.; Mensa-Wilmot, K. Discovery of a Carbazole-Derived Lead Drug for Human African Trypanosomiasis. Sci. Rep. 2016, 6, 32083.

(9) (a) Momin, A. A.; Urmode, T. D.; Bhosale, S. M.; Kusurkar, R. S. Short synthesis of carbazole alkaloids: Ekeberginine, murrayaquinone A, and glycozoline. Synth. Commun. 2016, 46, 1292-1298. (b) Forke, R.; Krahl, M. P.; Krause, T.; Schlechtingen, G.; Knölker, H.-J. Transition Metals in Organic Synthesis, Part 82. First Total Synthesis of Methyl 6-Methoxycarbazole-3-carboxylate, Glycomaurrol, the Anti-TB Active Micromeline, and the Furo[2,3-c]carbazole Alkaloid Eustifoline-D. Synlett 2007, 2007, 268-272.

(10) (a) Tian, X.; Song, L.; Hashmi, A. S. K. Synthesis of Carbazoles and Related Heterocycles from Sulfilimines by Intramolecular $\mathrm{C}-\mathrm{H}$ Aminations. Angew. Chem., Int. Ed. 2020, 59, 12342-12346. (b) Reddy, C. R.; Subbarao, M.; Sathish, P.; Kolgave, D. H.; Donthiri, R. R. One-Pot Assembly of 3-Hydroxycarbazoles via Uninterrupted Propargylation/Hydroxylative Benzannulation Reactions. Org. Lett. 2020, 22, 689-693. (c) Chen, S.; Li, Y.; Ni, P.; Huang, H.; Deng, G. J. Indole-to-Carbazole Strategy for the Synthesis of Substituted Carbazoles under Metal-Free Conditions. Org. Lett. 2016, 18, 5384-5387. (d) Guo, T.; Han, L.; Wang, T.; Lei, L.; Zhang, J.; Xu, D. Copper-Catalyzed Three-Component Formal $[3+1+2]$ Benzannulation for Carbazole and Indole Synthesis. J. Org. Chem. 2020, 85, 9117-9128. (e) Kundu, S.; Banerjee, A.; Maji, M. S. Brønsted Acid-Catalyzed Tandem Pinacol-Type Rearrangement for the Synthesis of $\alpha$-(3-Indolyl) Ketones by Using $\alpha$-Hydroxy Aldehydes. J. Org. Chem. 2019, 84, 16003-16012. (f) Aggarwal, T.; Sushmita; Verma, A. K. Recent advances in the synthesis of carbazoles from indoles. Org. Biomol. Chem. 2019, 17, 8330-8342.

(11) For an elegant, metal-free carbazole annulation cascade starting from indoles, see: Stepherson, J. R.; Ayala, C. E.; Tugwell, T. H.; Henry, J. L.; Fronczek, F. R.; Kartika, R. Carbazole Annulation via Cascade Nucleophilic Addition-Cyclization Involving 2-(Silyloxy)pentadienyl Cation. Org. Lett. 2016, 18, 3002-3005.

(12) (a) Deng, H.-D.; Mei, W.-L.; Wang, H.; Guo, Z.-K.; Dong, W.H.; Wang, H.; Li, S.-P.; Dai, H.-F. Carbazole alkaloids from the peels of Clausena lansium. J. Asian Nat. Prod. Res. 2014, 16, 1024-1028. Glycolizine has also been isolated from various other plant sources; for a review, see: (b) Knölker, H.-J.; Reddy, K. R. Isolation and Synthesis of Biologically Active Carbazole Alkaloids. Chem. Rev. 2002, 102, 4303-4427.

(13) The ${ }^{13} \mathrm{C}$-labeled substrate $4 \mathrm{a}^{*}$ was readily prepared by $\mathrm{Pd}$ catalyzed carbonylation of cinnamyl alcohol using $\left[{ }^{13} \mathrm{C}\right]$-formic acid. See: Fu, M.-C.; Shang, R.; Cheng, W.-M.; Fu, Y. Efficient PdCatalyzed Regio- and Stereoselective Carboxylation of Allylic Alcohols with Formic Acid. Chem. - Eur. J. 2017, 23, 8818-8822.

(14) For an earlier example of a diverted Bischler-Napieralski reaction involving indole ring opening, see: Frost, J. R.; Gaudillière, B. R. P.; Kauffmann, E.; Loyaux; Normand, N.; Petry, G.; Poirier, P.; Wenkert, E.; Wick, A. E. Intermolecular Trapping by Indole of a Spiroindolenine Intermediated Formed during the Bischler-Napieralski Cyclisation of N-Acetyltryptamine. Heterocycles 1989, 28, 175182.

(15) Saya, J. M.; Ruijter, E.; Orru, R. V. A. Total Synthesis of Aspidosperma and Strychnos Alkaloids through Indole Dearomatization. Chem. - Eur. J. 2019, 25, 8916-893. 